\title{
Poda do pseudocaule e doses de nitrogênio e boro na produção de mudas de bananeira 'Pacovan'
}

\author{
Pseudostem pruning and doses of nitrogen and boron on the \\ production of suckers of 'Pacovan' banana tree
}

\author{
José Pires Ribeiro Nóbrega ${ }^{1}$; Walter Esfrain Pereira ${ }^{2 *}$; Thiago Jardelino Dias ${ }^{3}$; \\ Roberto Wagner Cavalcante Raposo ${ }^{4}$; Raunira da Costa Araújo ${ }^{5}$; \\ Francisco Assis de Oliveira ${ }^{4}$
}

\begin{abstract}
Resumo
O Brasil é o segundo maior produtor mundial de banana, entretanto, a expansão da bananicultura encontra uma série de entraves, dentre os quais a falta de mudas em quantidade e qualidade, necessárias para implantação de novos bananais. O objetivo deste experimento foi avaliar a influência da poda no pseudocaule com eliminação da gema apical do rizoma e de doses de nitrogênio e boro sobre a produção e o crescimento de mudas de bananeira. $\mathrm{O}$ experimento foi realizado no Centro de Formação de Tecnólogos da UFPB. O delineamento foi em blocos casualizados, com quatro blocos e nove plantas matrizes por parcela, sendo duas plantas úteis. Os fatores avaliados foram doses de $\mathrm{N}\left(0\right.$ a $\left.240 \mathrm{~g} \mathrm{planta}^{-1}\right)$ e de B (0 a 2,2 g planta $\left.^{-1}\right)$ combinados mediante a matriz experimental Composto Central de Box, originando nove tratamentos, aplicados com poda e sem poda no pseudocaule da planta matriz. Os dados foram submetidos à análise de variância e de regressão. A poda do pseudocaule da planta principal, com a eliminação da gema apical do rizoma aumentou o número de perfilhos, com maior crescimento, exceto do diâmetro do rizoma, o qual diminuiu. Os teores foliares de clorofila total e de B também foram diminuídos nos perfilhos das bananeiras podadas. Para a produção de mudas da bananeira 'Pacovan', recomenda-se poda do pseudocaule da planta principal, com eliminação da gema apical do rizoma e aplicação de $\mathrm{N}$.
\end{abstract}

Palavras-chave: Musa sp, propagação, perfilhos, clorofila

\begin{abstract}
Brazil is the second world producer of banana, however, the expansion of the banana crop has many difficulties, as the lack of suckers in amount and quality, necessary for implantation of new banana plantations. The objective of this research work was to evaluate the influence of the pseudostem pruning with elimination of the apical meristem of the rhizome and of doses of nitrogen and boron on the production and growth of banana suckers. The experiment was carried out at Centro de Formação de Tecnólogos - UFPB, state of Paraíba. The experimental design was randomized blocks, with four
\end{abstract}

${ }^{1}$ Mestre em Agronomia, CCA/UFPB, Campus II, Cidade Universitária, Areia-PB, Cep: 58397-000. E-mail: jpiresrn@yahoo.com.br

${ }^{2}$ Prof. Associado do Departamento de Ciências Fundamentais e Sociais, CCA/UFPB, Campus II, Cidade Universitária, Areia-PB, Cep: 58397-000. Fone: 83-3362-2300. E-mail: wep@cca.ufpb.br. Bolsista do CNPq.

${ }^{3}$ Mestre em Manejo e Conservação do Solo e Água, Doutorando em Agronomia, CCA/UFPB, Campus II, Cidade Universitária, Areia-PB, Cep: 58397-000. E-mail: tjardelino@hotmail.com

${ }^{4}$ Prof. Adjunto do Departamento de Solos e Engenharia Rural, CCA/UFPB, Campus II, Cidade Universitária, Areia-PB, Cep: 58397-000. Fone: 83-3362-2300. E-mail: rwcraposo@cca.ufpb.br; oliveira@cca.ufpb.br

${ }_{5}^{5}$ Prof Adjunta do Centro de Formação de Tecnólogos, UFPB/Campus III, Bananeiras - PB. Cep: 58220-000, E-mail: raunira@cft. ufpb.br

* Autor para correspondência 
blocks and nine mother plants by experimental unit, being two useful plants. The evaluated factors were doses of $\mathrm{N}$ ( 0 to $240 \mathrm{~g}$ plant $\left.^{-1}\right)$ and of B ( 0 to 2,2 $\left.\mathrm{g} \mathrm{plant}^{-1}\right)$ combined by the use of the experimental matrix 'Central Composite', originating nine treatments, applied with pruning and without pruning of the mother plant pseudostem. The data were submitted to the analysis of variance and regression. In the plants with pruning, it was reduced the sucker number, which presented smaller growth, on the other hand, it increased the concentration of total chlorophyll. For the production of 'Pacovan' banana suckers, it is recommended the pruning of the mother plant pseudostem with elimination of the rhizome apical meristem and the application of $\mathrm{N}$.

Key words: Musa sp, propagation, sucker, chlorophyll

\section{Introdução}

A banana ocupa o segundo lugar em volume de frutas produzidas no Brasil, perdendo apenas para a laranja, sendo cultivada predominantemente em pequenas propriedades, onde são colhidos $60 \%$ da produção nacional, tendo grande importância na fixação do homem no campo e na geração de emprego e renda, especialmente para as camadas carentes da população (BERNARDO et. al., 2004; EMBRAPA, 2005). A despeito dessa grande produção, a bananicultora nacional enfrenta sérios problemas, refletindo em baixa produtividade, em razão da falta de variedades comerciais, com porte adequado, resistentes a pragas e doenças, ao manejo inadequado do sistema solo-água-planta, especialmente no que diz respeito a espaçamentos, adubações, desbaste, produção e seleção de mudas, e controle de pragas e doenças (ANDRADE et al., 2009).

No Brasil, além dos genótipos do subgrupo Cavendish, diversas variedades "regionais" são consideradas de interesse comercial, levando-se em conta a preferência do consumidor (SOUTO et al., 1999). Nas últimas décadas, tem sido crescente a ampliação da área plantada com a bananeira cultivar Pacovan (Musa sp. AAB, subgrupo Prata), a qual ocupa uma expressiva fatia do mercado Nordestino, parte desta antes ocupada pela bananeira 'Prata' (Musa sp. AAB), variedade semelhante, mas menos produtiva. Linden (1985) afirma que, na microrregião do Brejo Paraibano, a cultivar Pacovan destaca-se em termos de área plantada em relação às demais. Essa predominância ainda perdura na atualidade.
Não obstante a grande produção nacional, o crescimento da bananicultura encontra uma série de obstáculos, que têm contribuído para os baixos índices de produtividade e qualidade do fruto. Dentre esses entraves, encontra-se a falta de mudas em quantidade e qualidade necessárias para implantação de novos bananais (RUGGIERO; GOTTARDI, 1997). A grande expansão desta cultura, ocorrida nos últimos anos, concorreu para uma forte demanda por mudas, muitas vezes de origem e qualidade duvidosas (SILVA; SOUTO; MENEGUCCI, 1999). Todavia, a qualidade da muda é de suma importância, pois está relacionada à precocidade de produção, uniformidade do material, vigor, sanidade das plantas, custos de produção e produtividade (COUCEIRO; SIQUEIRA; PEREIRA, 2001).

A bananeira é uma planta exigente em nutrientes, não só por produzir grande massa vegetativa, mas também por apresentar elevadas quantidades de elementos absorvidos pela planta e exportados pelos frutos (SILVA; SOUTO; MENEGUCCI, 1999).

O nitrogênio exerce grande importância no início do desenvolvimento da bananeira até a emissão da inflorescência, havendo diferenciação entre as partes vegetativas que constituem a bananeira, quanto à concentração e extração ou acúmulo de nutrientes. Entre rizoma, pseudocaule e folhas, as maiores concentrações de nitrogênio encontram-se no pseudocaule (DINIZ et al., 1999). O nitrogênio, é ainda, uns dos componentes mais importantes na célula viva, participando das funções vitais da planta como produção de nucleotídeos, coenzimas e um grande número de outros compostos nos vegetais 
(MEYER et al., 1983), tais como aminas, amidas, amino-açúcares, purinas e pirimidinas, alcalóides, vitaminas, pigmentos e outros (DECHEN; BATAGLIA; SANTOS, 1995).

$\mathrm{Na}$ propagação de mudas de bananeira, a deficiência do boro promove dificuldade de brotação de mudas e deformações morfológicas nas folhas novas. Essas deformações são limbos estreitos com ondulações nos bordos e às vezes somente a nervura central permanece. Promove ainda outros sintomas tais como necrose nas margens das folhas sem clorose prévia, principalmente na ponta, a qual se encarquilha, clorose internerval e estrias perpendiculares às nervuras secundárias na face inferior e aparecimento de muitos filhotes com os sintomas ainda mais acentuados. Em casos extremos de carência, ocorre a paralisação do crescimento, mas, por outro lado, o excesso de boro pode acarretar clorose marginal seguida de necrose nas folhas (LAHAV, 1995).

Portanto, na produção de mudas de bananeira é fundamental a manutenção do equilíbrio nutricional e de métodos de propagação que possam proporcionar mudas de melhor qualidade e elevada a taxa de multiplicação, de maneira a contribuir para o desenvolvimento da bananicultura, garantir a fidelidade genética do material e disponibilizar produtos de melhor qualidade e acessíveis aos agricultores (SOUZA; CORDEIRO; TRINDADE, 2000).

O objetivo desta pesquisa foi avaliar a influência da poda do pseudocaule, com aplicação de doses de nitrogênio e boro sobre a produção, crescimento e o teor de clorofila de perfilhos (mudas) da bananeira 'Pacovan'.

\section{Material e Métodos}

Este experimento foi conduzido no Centro de Formação de Tecnólogos (CFT) da Universidade Federal da Paraíba (UFPB), Estado da Paraíba, no período de junho de 2005 a fevereiro de 2006. A temperatura e umidade relativa do ar no período de execução do experimento variaram entre $20-26^{\circ} \mathrm{C}$ e 76-93\%, respectivamente.

As mudas de bananeira, cultivar Pacovan (Musa sp. AAB, subgrupo Prata), foram originárias de cultura de tecidos de ápices caulinares e adquiridas, com cerca de 6 a $7 \mathrm{~cm}$ de altura. Procedeu-se a aclimatização das mudas em viveiros, realizandose a repicagem das mudas em recipientes de polietileno preto com $20 \mathrm{~cm}$ de largura e $30 \mathrm{~cm}$ comprimento, sanfonados e perfurados em seu terço inferior, contendo substrato peneirado e solarizado, composto por terra argilo-arenosa de superfície e composto orgânico vegetal, na proporção de 3:1, respectivamente (KATAN et al., 1976; RICCI et al., 1999).

O tempo de aclimatização das mudas foi de 81 dias, sendo um período de 61 dias sob telado, com 50\% de luminosidade, e outro de 20 dias em viveiro a céu aberto, para completarem o seu "endurecimento", até o plantio no campo. Durante o desenvolvimento das mudas, foi realizada adubação em cobertura, via solo, aos 42 dias, aplicandose por planta, em círculo e próximo as bordas dos recipientes, uma mistura composta por $2,5 \mathrm{~g}$ de uréia, 4,0 g de superfosfato simples e 1,2 $\mathrm{g}$ de cloreto de potássio. Foram realizadas ainda, quatro adubações via aplicação foliar, com intervalos de 15 dias entre as aplicações, iniciando-se no $35^{\circ}$ dia após a repicagem com uréia $\left(2,5 \mathrm{~g} \mathrm{~L}^{-1}\right)$ mais sulfato de magnésio $\left(2,5 \mathrm{~g} \mathrm{~L}^{-1}\right)$; a segunda repetindo a aplicação da primeira; a terceira utilizando uréia (3,0 $\left.\mathrm{g} \mathrm{L}^{-1}\right)$ mais sulfato de zinco $\left(2,0 \mathrm{~g} \mathrm{~L}^{-1}\right)$; e, a quarta aplicando-se sulfato de cobre $\left(2,5 \mathrm{~g} \mathrm{~L}^{-1}\right)$ mais cal hidratada $\left(5,0 \mathrm{~g} \mathrm{~L}^{-1}\right)$.

As irrigações foram realizadas periodicamente, sendo que nos primeiros 15 dias de aclimatização as regas tinham maior freqüência, porém aplicavase menor lâmina de água, utilizando pulverizador costal manual, para simular uma nebulização sobre as folhas, em intervalos de aplicação de aproximadamente uma hora, os quais foram 
sendo ampliados com o avanço do processo de aclimatação. Posteriormente, passou-se a utilizar o sistema de irrigação por microaspersão, a intervalos menos freqüentes.

Os tratamentos foram distribuídos em delineamento de blocos casualizados, com quatro blocos e nove plantas matrizes por parcela (composta por três linhas com três plantas cada), sendo duas plantas úteis (na linha central) por unidade experimental. Os fatores avaliados foram doses de nitrogênio $(\mathrm{N})$ e de boro (B) combinados de acordo com a matriz experimental Composto Central de Box, originando nove tratamentos (Tabela 1), os quais foram combinadas fatorialmente com dois tipos de poda no pseudocaule: poda a $10 \mathrm{~cm}$ acima da superfície do solo e sem poda, totalizando 18 tratamentos.

A caracterização química e física do solo foi realizada antes da implantação do experimento, procedendo-se a coleta de amostras compostas às profundidades de 0 a $20 \mathrm{~cm}$ e de 20 a $40 \mathrm{~cm}$, cujos resultados estão apresentados na (Tabela 2).

Tabela 1. Níveis e doses de Nitrogênio (N) e de Boro (B) combinados de acordo com a matriz experimental Composto Central de Box.

\begin{tabular}{cccc}
\hline & Níveis & \multicolumn{2}{c}{ Doses $\left(\mathbf{g ~ p l a n t a}^{-1}\right.$ ou família) $^{-}$} \\
\hline $\mathbf{N}$ & $\mathbf{B}$ & $\mathbf{N}$ & $\mathbf{B}$ \\
\hline-1 & -1 & 35 & 0,32 \\
-1 & 1 & 35 & 1,88 \\
1 & -1 & 205 & 0,32 \\
1 & 1 & 205 & 1,88 \\
$-1,41$ & 0 & 0 & 1,1 \\
0 & $-1,41$ & 120 & 0 \\
1,41 & 0 & 240 & 1,1 \\
0 & 1,41 & 120 & 2,2 \\
0 & 0 & 120 & 1,1 \\
\hline
\end{tabular}

Tabela 2. Características químicas e físicas do solo da área experimental, nas profundidades de 0 a $20 \mathrm{~cm}$ e de 20 a $40 \mathrm{~cm}$.

\begin{tabular}{|c|c|c|c|c|c|c|c|c|c|}
\hline Profundidade & $\mathrm{pH}\left(\mathrm{H}_{2} 0\right)$ & $\mathrm{P}$ & \multicolumn{2}{|c|}{$\mathrm{S}-\mathrm{SO}_{4}^{-2}$} & $\mathrm{~K}^{+}$ & $\mathrm{Na}^{+}$ & $\mathrm{H}^{+}+\mathrm{Al}^{+3}$ & & $\mathrm{Al}^{+3}$ \\
\hline$--\mathrm{cm}--$ & $(1: 2,5)$ & \multicolumn{8}{|c|}{ 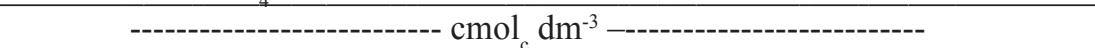 } \\
\hline $0-20$ & 6,2 & 0,06 & \multicolumn{2}{|c|}{0,03} & 0,20 & 0,12 & \multicolumn{2}{|c|}{2,48} & 0,00 \\
\hline $20-40$ & 5,0 & 0,01 & \multicolumn{2}{|c|}{0,13} & 0,19 & 0,10 & \multicolumn{2}{|l|}{4,79} & 0,50 \\
\hline Profundidade & $\mathrm{Ca}^{+2}$ & \multicolumn{2}{|c|}{$\mathrm{Mg}^{+2}$} & SB & \multicolumn{2}{|c|}{ CTC } & M.O. & \multicolumn{2}{|r|}{$\mathrm{V}$} \\
\hline$--\mathrm{cm}-$ & ---- & \multicolumn{5}{|c|}{----- $\mathrm{cmol}_{\mathrm{c}} \mathrm{dm}^{-3}$--------------- } & \multicolumn{2}{|l|}{$-\mathrm{g} \mathrm{kg}^{-1}-$} & $-\%-$ \\
\hline $0-20$ & 3,75 & \multicolumn{2}{|c|}{1,55} & 5,62 & \multicolumn{2}{|c|}{8,10} & 37,89 & \multicolumn{2}{|r|}{69,38} \\
\hline $20-40$ & 0,85 & \multicolumn{2}{|c|}{0,75} & 1,89 & \multicolumn{2}{|c|}{6,68} & 19,05 & \multicolumn{2}{|r|}{28,29} \\
\hline Profundidade & $\mathrm{B}$ & \multicolumn{2}{|c|}{$\mathrm{Fe}$} & & \multicolumn{2}{|c|}{$\mathrm{Cu}$} & In & \multicolumn{2}{|r|}{$\mathrm{Zn}$} \\
\hline -- $\mathrm{cm}--$ & & \multicolumn{8}{|c|}{ 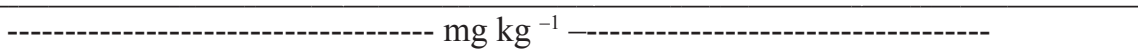 } \\
\hline $0-20$ & 0,17 & \multirow{2}{*}{\multicolumn{2}{|c|}{$\begin{array}{l}43,04 \\
42,97\end{array}$}} & \multicolumn{2}{|c|}{1,04} & \multicolumn{2}{|c|}{29,36} & \multicolumn{2}{|c|}{15,62} \\
\hline $20-40$ & 0,52 & & & & 0,11 & & 81 & & 4,85 \\
\hline \multirow{2}{*}{ Profundidade } & \multicolumn{2}{|c|}{ Areia } & \multirow{2}{*}{ Silte } & \multirow{2}{*}{ Argila } & \multirow{2}{*}{$\mathrm{AD}$} & \multirow{2}{*}{ GF } & \multirow{2}{*}{ Ds } & \multirow{2}{*}{$\mathrm{Dp}$} & PT \\
\hline & Grossa & Fina & & & & & & & $P 1$ \\
\hline -- $\mathrm{cm}--$ & & 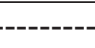 & $-\mathrm{g} \mathrm{kg}^{-1}$ & --------- & 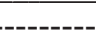 & & $-\mathrm{g} \mathrm{cm}^{-3}$ & $3-$ & $\mathrm{m}^{3} \mathrm{~m}^{-3}$ \\
\hline $0-20$ & 408 & 197 & 41 & 354 & 51 & 856 & 1,31 & 2,60 & 0,50 \\
\hline $20-40$ & 324 & 191 & 69 & 416 & 82 & 803 & 1,23 & 2,61 & 0,53 \\
\hline
\end{tabular}

AD: Argila dispersa; GF: Grau de Floculação; Ds: Densidade do solo; PT: porosidade Total. 
O preparo da área experimental foi constituído de aração, gradagem e abertura das covas nas dimensões de 40 x 40 x $40 \mathrm{~cm}$ (ALVES; LIMA, 2000), obedecendo a espaçamentos de viveiro de 1,5 x 1,5 m (SILVA; SOUTO; MENEGUCCI, 1999), em configuração quadrangular(SOTO-BALLESTERO, 1992). Cada bloco e suas respectivas unidades experimentais foram constituídos por três linhas de plantio.

As covas foram preparadas 30 dias antes do transplantio das mudas em campo com material composto do solo retirado dos locais das respectivas covas, adicionando $80 \mathrm{~g} \mathrm{cova}^{-1}$ de $\mathrm{P}_{2} \mathrm{O}_{5}$, na forma de superfosfato simples e $40 \mathrm{~g}$ cova $^{-1}$ de $\mathrm{K}_{2} \mathrm{O}$, na forma de cloreto de potássio, além do calcário dolomítico (715 g cova $\mathrm{g}^{-1}$ com PRNT 65\%) e esterco bovino curtido $\left(5,0 \mathrm{dm}^{-3} \operatorname{cova}^{-1}\right)$, que após homogeneização foram acondicionado no interior das respectivas covas (ALVES et al., 1986).

As mudas (plantas matrizes) de bananeira foram plantadas quando apresentavam cerca de 30 a $35 \mathrm{~cm}$ de altura, e manejadas por sistema de irrigação localizado (microaspersão), aplicando-se o suprimento de água de acordo com a necessidade da cultura, os índices de precipitação e a disponibilidade de água acumulada nos reservatório da área experimental. Desta forma, aplicou-se em

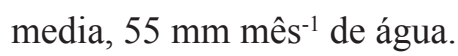

Os adubos foram aplicados em cobertura, incorporando superficialmente em faixa circular com cerca de $10 \mathrm{~cm}$ de largura na primeira aplicação e a $20 \mathrm{~cm}$ de largura, nas demais, da base do pseudocaule da planta matriz e, ou da brotação lateral (BORGES; OLIVEIRA, 2000). As doses foram fracionadas aplicando-se a primeira parcela ( $25 \%$ do $\mathrm{N}$ e $50 \%$ do $\mathrm{B}$ ) aos 40 dias após o plantio das mudas; a segunda ( $25 \%$ do $\mathrm{N}$ e $50 \%$ do $\mathrm{B}$ ), aos 78 dias; e, a terceira e a quarta ( $25 \%$ do N), aos 117 e 148 dias, respectivamente.

Para quebrar a dominância apical e favorecer a brotação lateral e a produção de mudas, realizouse a poda a $10 \mathrm{~cm}$ acima do nível do solo, aos 151 dias após o plantio, procedendo-se previamente a primeira coleta de perfilhos (145 dias após o plantio) e a última aplicação do $\mathrm{N}$ em cobertura (148 dias após o plantio). Imediatamente após essa poda, foi feita a eliminação da gema apical de crescimento do rizoma, com auxílio da ferramenta denominada "lurdinha" (MOREIRA, 1999), desinfetada com água clorada.

Com intervalos de 28 dias, foram realizadas quatro coletas de perfilhos: aos 145; 173; 201; e, 229 dias após o plantio. Isso foi realizado com auxílio de cavador, desinfetado com água clorada, e de régua graduada em mm. Foram separados da planta matriz (coletados), os perfilhos ou rebentos com altura igual ou superior a $15,0 \mathrm{~cm}$, determinada entre a distância da superfície do solo ao ponto de interseção das duas últimas folhas (SANTOS, 2002).

Após a separação da planta matriz, através de corte bem rente à mesma, os rizomas foram lavados com água e, embalados em sacolas plásticas etiquetadas, os perfilhos foram encaminhados para as análises no Laboratório de Controle de Qualidade de Alimentos do CFT/UFPB.

Para os perfilhos coletados aos 145 dias após o plantio (primeira coleta) foram avaliados apenas o número de perfilhos produzidos, pois, naquela oportunidade ainda não havia sido feito o último parcelamento de nitrogênio em cobertura e nem a poda com eliminação da gema apical do rizoma.

No entanto, quando todas as atividades relativas aos tratamentos foram concluídas, os perfilhos coletados aos 173, 201 e 229 dias após o plantio, foram avaliadas as seguintes características: número médio de perfilhos produzidos por planta matriz; altura média do pseudocaule dos perfilhos; diâmetro médio do rizoma dos perfilhos; massa média da matéria seca foliar dos perfilhos adotando procedimento proposto pela Embrapa (1999); e, teores foliares de clorofila total pelo método de Arnon (1949), dos perfilhos coletados aos 201 e 229 dias após o plantio. 
Os dados obtidos foram submetidos à análise de variância e de regressão. Os efeitos do $\mathrm{N}$ e do B foram avaliados mediante regressão polinomial, enquanto os efeitos das podas foram avaliados pelo teste F. Em face da heterogeneidade das variâncias, transformou-se os dados referentes à variável número de perfilhos em $\sqrt{X+1}$.

\section{Resultados e Discussão}

Constatou-se efeito significativo de poda sobre o número de perfilhos produzidos por planta matriz,

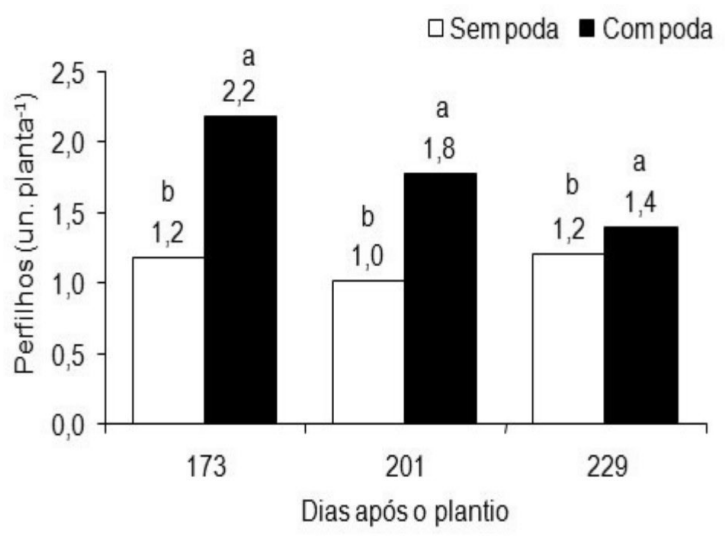

aos 173, 201 e 229 dias após o plantio. Não foi verificada influência significativa da combinação $\mathrm{N}$ e B nem da interação entre N e B e poda.

$\mathrm{Na}$ (Figura 1), observa-se que a partir de 173 dias após o plantio, as plantas podadas produziram significativamente mais perfilhos do que as plantas não podadas, e que, os perfilhos das plantas de bananeira 'Pacovan' com poda apresentaram maior altura de pseudocaule do que os perfilhos das plantas sem poda. O maior número de perfilhos e a maior altura foram observados aos 173 dias após o plantio, em plantas podadas.

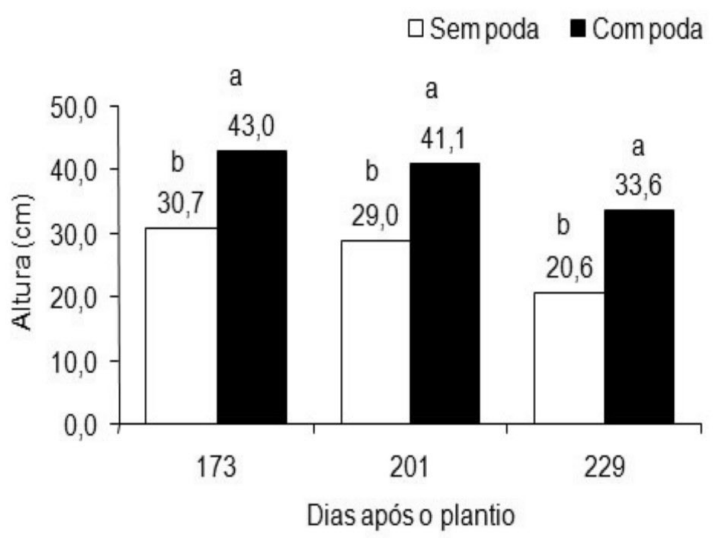

Figura 1. Número de perfilhos e altura de plantas da bananeira 'Pacovan', com e sem poda, em três períodos pósplantio. " Médias com letras diferentes diferem pelo teste $\mathrm{F}$, em cada período pós-plantio.

Para o número de perfilhos produzidos por planta podada aos 201 dias após o plantio, pode-se verificar que foi significativa a regressão linear (Figura 2), indicando que à medida que aumentaram as doses de $\mathrm{N}$, maiores foram os valores para produção de perfilhos por planta, cujo incremento foi de 0,002 perfilhos por cada $1 \mathrm{~g}$ planta $^{-1}$ de $\mathrm{N}$ adicionada ao solo.

O maior número de perfilhos produzido pelas plantas podadas em relação às não podadas ratifica a hipótese do controle hormonal de desenvolvimento de gemas laterais pelo meristema apical, sendo a auxina o principal hormônio envolvido nesse processo, representado possivelmente, pelo ácido indolacético, sintetizado na região apical e transportado para os meristemas laterais (AWAD;
CASTRO, 1983). A dominância apical se manifesta por inibição do crescimento das gemas axilares ou laterais, sendo os meristemas apicais e folhas jovens os principais sítios de síntese de auxinas na parte aérea da planta, ocorrendo uma ação indireta na dominância de gemas e brotos (PHILLIPS, 1969).

Nas plantas também podadas, aos 229 dias após o plantio o B exerceu influência linear decrescente sobre o número de perfilhos produzidos por planta, diminuindo o número de perfilhos com o aumento das doses de B aplicadas (Figura 2). Esse comportamento acorreu provavelmente devido à disponibilidade de B no solo e ao acúmulo foliar, provocando decréscimo do teor foliar de nitrogênio (AZEVEDO et al., 2002; PAVINATO et al., 2009). 

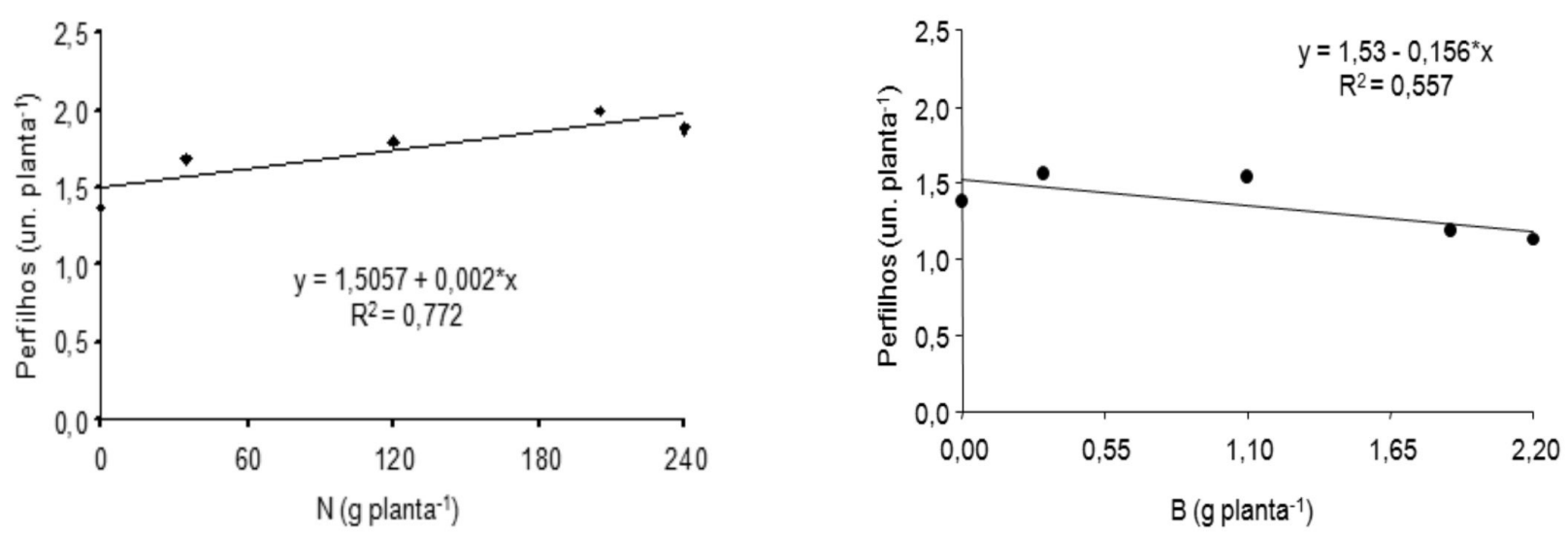

Figura 2. Efeito de doses de nitrogênio e de boro sobre o número de perfilhos de plantas da bananeira 'Pacovan', com poda, aos 201 e aos 229 dias após o plantio, respectivamente. *: Significativo a 5\% pelo teste F.

Esses resultados são compatíveis com relatos de vários autores, tais como Silva, Souto e Menegucci, (1999) e Borges e Oliveira (2000), os quais afirmam que o $\mathrm{N}$ é o segundo elemento mais importante para a bananeira e favorece a emissão e o crescimento de filhotes ou rebentos. Uma possível explicação para esse efeito benéfico do $\mathrm{N}$ foi o fato de que o aumento das doses de $\mathrm{N}$ incrementou a massa da matéria seca foliar (Figura 7), disponibilizando maior quantidade de fotoassimilados. A despeito disso, Fontes et al. (2003) obtiveram resultados contraditórios, concluindo que houve diminuição na emissão de filhotes com o incremento das doses de N.

Vários outros autores conseguiram, através da propagação rápida in vivo, obter resultados mais promissores do que os desta pesquisa. No entanto, é conveniente ressaltar que, além das especificidades da metodologia usada particularmente, adubações e condições edafoclimáticas locais, entre outras, existe o importante fator variedade, o qual, segundo constatações de pesquisas (RUGGIERO et al., 2000; SILVA; CORDEIRO, 2000), apresenta diferenças de desempenho na emissão de rebentos ou perfilhos.
Estudo sobre a propagação da bananeira através de morfogênese indireta in vivo resultou em número médio de 5,$0 ; 4,0 ; 5,2 ; 5,0 ; 4,1$; e 4,1 rebentos por rizoma, após 150 dias, respectivamente, para as variedades Nanicão, Maçã, Prata-Anã, Fhia1 e Fhia-18, ratificando, assim, a existência de variedades mais eficientes que outras, em relação à produção de mudas (RUGGIERO et al., 2000; SILVA; CORDEIRO, 2000). Constatou-se também que a primeira brotação, além de ser menos trabalhosa, resultou em maior produção de rebentos (RUGGIERO et al., 2000).

Aos 229 dias após o plantio, a altura do pseudocaule dos perfilhos das plantas não podadas comportou-se de maneira linear positiva em função das doses de $\mathrm{B}$ testadas, apresentando aumento estimado de $1,78 \mathrm{~cm}$ para cada incremento de $1 \mathrm{~g}$ planta $^{-1}$ de B adicionada ao solo (Figura 3).

Aos 201 dias após o plantio verificou-se efeito linear do B (Figura 3) sobre a altura do pseudocaule de perfilhos de plantas podadas, indicando que à medida que aumentaram as doses de $\mathrm{B}$, diminuiu a altura do pseudocaule dos perfilhos, cujo decréscimo foi de 4,93 cm para cada incremento de $1 \mathrm{~g} \mathrm{planta}^{-1}$ de $\mathrm{B}$, resultado semelhante ao obtido para número de perfilhos produzidos por planta. 

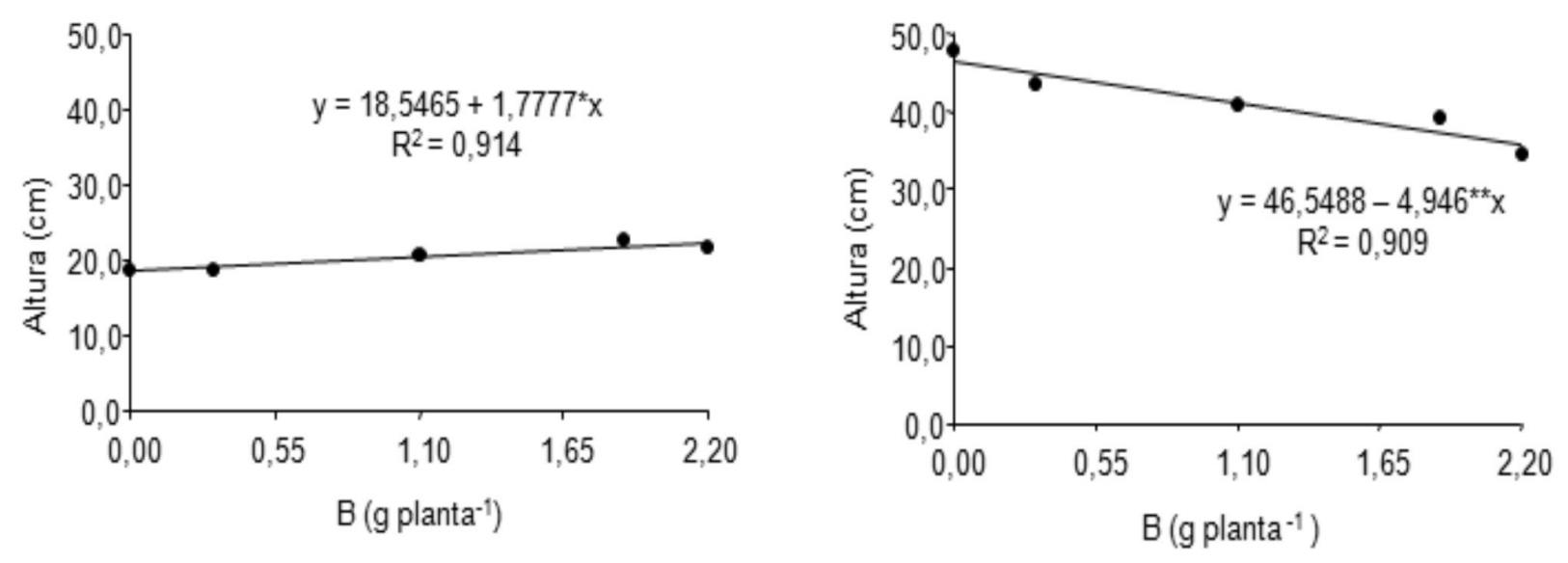

Figura 3. Efeito de doses de boro sobre a altura do pseudocaule de perfilhos de plantas da bananeira 'Pacovan', sem poda, aos 229 dias e com poda, aos 201 dias após o plantio. ***: Significativo a 5 e a 1\%, respectivamente, pelo teste F.

Verificou-se influência significativa da perfilhos com maior diâmetro de rizoma do que as combinação N e B sobre o diâmetro do rizoma dos plantas podadas, com diferenças significativas de perfilhos de bananeira 'Pacovan' apenas aos 201 2,$8 ; 4,2 ;$ e $3,0 \mathrm{~cm}$ aos 173,201 e 229 dias após o dias após o plantio. O efeito de poda foi significativo plantio, respectivamente. Os maiores diâmetros sobre o diâmetro do rizoma dos perfilhos, aos 173, 201 e 229 dias após o plantio (Figura 4).

As plantas que não foram podadas apresentaram de rizoma dos perfilhos, $9,9 \mathrm{~cm}$ e $9,8 \mathrm{~cm}$, foram observados, respectivamente, aos 201 e 173 dias após o plantio, em plantas sem poda (Figura 4).
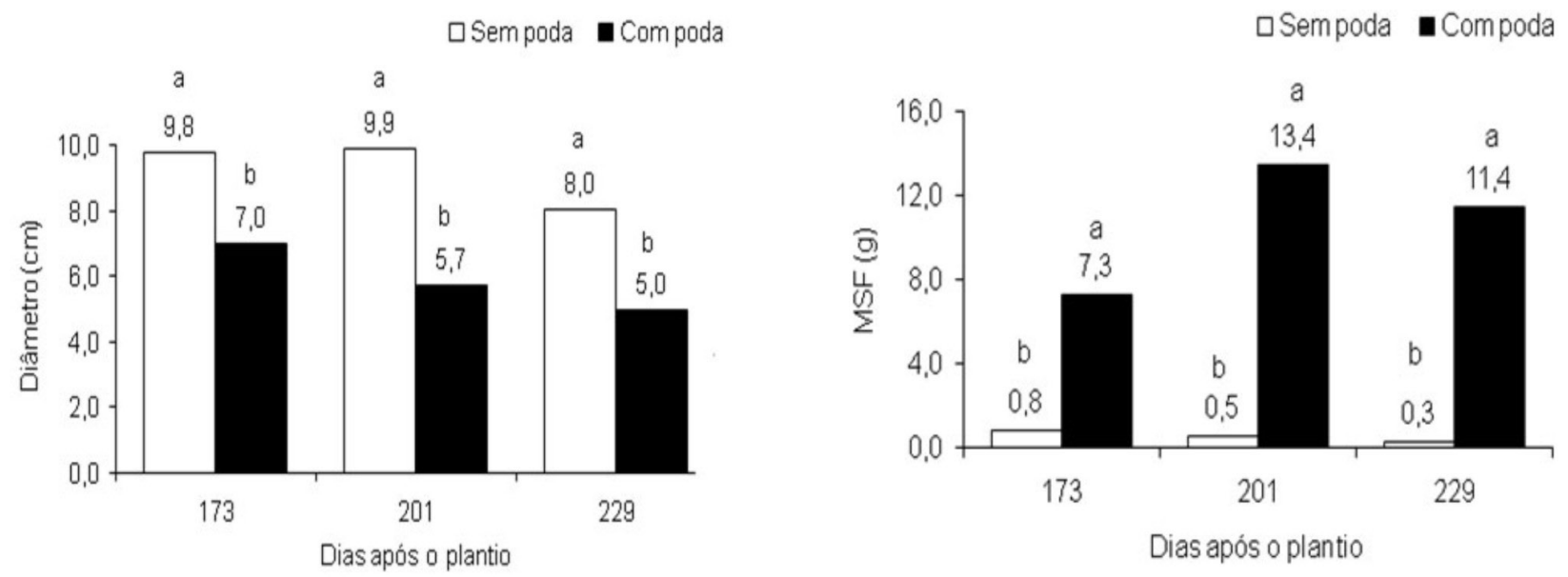

Figura 4. Diâmetro do rizoma e peso da matéria seca foliar (MSF) dos perfilhos de plantas da bananeira 'Pacovan', com e sem poda, em três períodos pós-plantio. Médias com letras diferentes diferem pelo teste $\mathrm{F}$ a $1 \%$, em cada período pós-plantio. 
As doses de $\mathrm{N}$ e de $\mathrm{B}$ não exerceram influência no diâmetro do rizoma de perfilhos das plantas não podadas, em nenhum período pós-plantio estudado. No entanto, nas plantas podadas, a aplicação de $\mathrm{N}$ e B teve efeito linear aos 201 dias após o plantio.

Observa-se na Figura 5, que aos 201 dias após o plantio, à medida que aumentaram as doses de $\mathrm{N}$ e $\mathrm{B}$, diminuiu o diâmetro de rizoma dos perfilhos das plantas com poda, à razão de $4,0 \mathrm{~mm}$ e de 0,54 $\mathrm{cm}$, respectivamente, para cada incremento de $1 \mathrm{~g}$ planta $^{-1}$ de N e B adicionada ao solo.

Foi constatada influência de poda sobre o peso da matéria seca foliar (MSF) dos perfilhos de plantas de bananeira, nos três períodos pós-plantio estudados. Apenas nas plantas podadas a aplicação das doses de $\mathrm{N}$ e de $\mathrm{B}$ teve influência sobre o peso da MSF dos perfilhos aos 173 e 201 dias após o plantio, respectivamente (Figura 6).
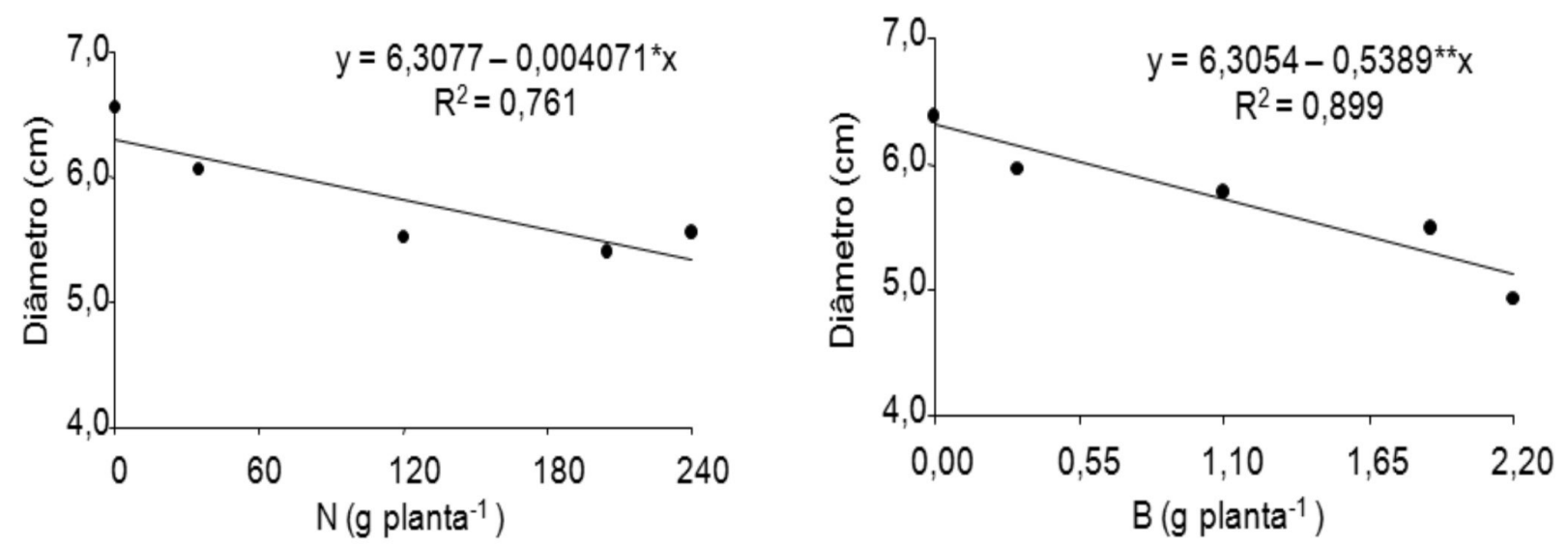

Figura 5. Efeito de doses de nitrogênio e do boro sobre o diâmetro do rizoma de perfilhos de plantas da bananeira 'Pacovan', com poda, aos 201 dias após o plantio. ***: Significativo a 5 e a 1\%, respectivamente, pelo teste F.

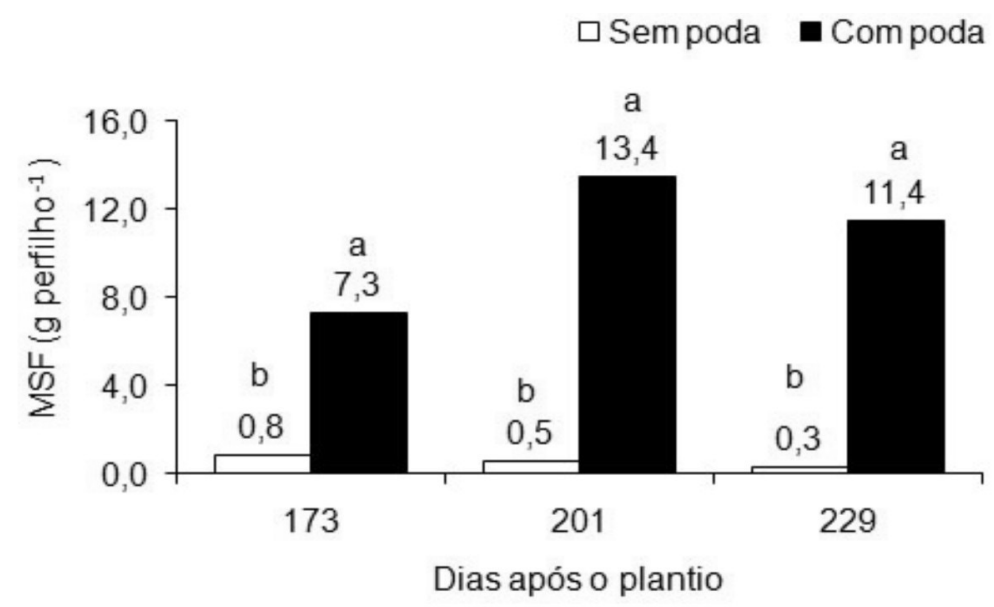

Figura 6. Efeito de doses de nitrogênio e do boro sobre a matéria seca foliar (MSF) dos perfilhos de plantas da bananeira 'Pacovan', com poda, aos 173 e aos 201 dias, respectivamente, após o plantio. Médias com letras diferentes diferem pelo teste $\mathrm{F}$ a $1 \%$, em cada período pós-plantio. 
Verificou-se uma resposta positiva da poda sobre o peso da MSF dos perfilhos. A partir de 173 dias após o plantio, os perfilhos das plantas com poda apresentaram maiores pesos da matéria seca de folhas do que os perfilhos das plantas sem poda (Figura 6). O maior peso da MSF dos perfilhos ocorreu aos 201 dias após o plantio, nas plantas com poda. A poda, de modo geral, aumentou o peso da MSF dos perfilhos de plantas da bananeira 'Pacovan'.

Nas plantas com poda, houve aumento linear do peso da matéria seca foliar dos perfilhos à medida que aumentaram as doses de N, aos 173 dias após

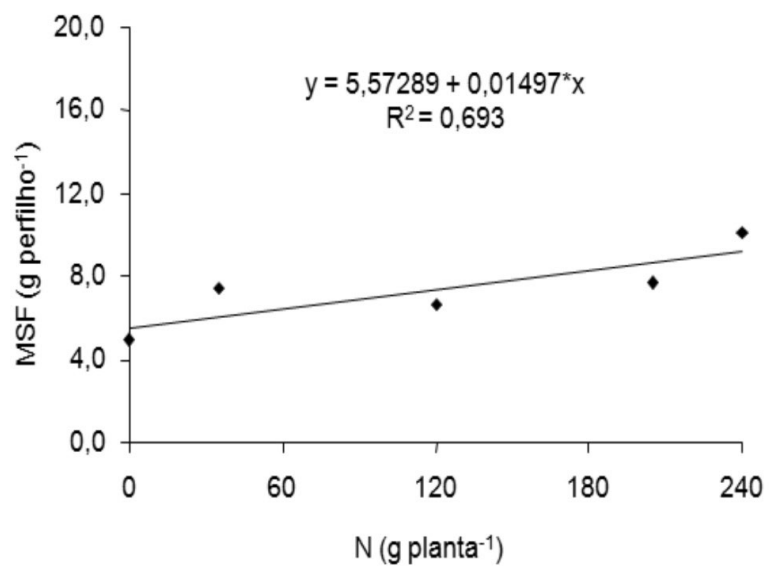

o plantio (Figura 7). O aumento observado foi de $15 \mathrm{mg}$ para cada incremento de $1 \mathrm{~g}$ planta $^{-1}$ de $\mathrm{N}$ adicionada ao solo. Esse aumento de matéria seca, em perfilhos de bananeira 'Pacovan', favorecido pelo N, está em consonância com relatos de Borges et al. (1997), Silva, Souto e Menegucci (1999) e Borges e Oliveira (2000), quando citam que o N é muito importante para o crescimento vegetativo da bananeira

Também nas plantas com poda, aos 201 dias após o plantio, o peso da matéria seca foliar dos perfilhos seguiu uma tendência linear negativa em função das doses de B (Figura 7), sendo o decréscimo de 3,72 g para cada $1 \mathrm{~g}$ planta $^{-1}$ de B adicionada ao solo.

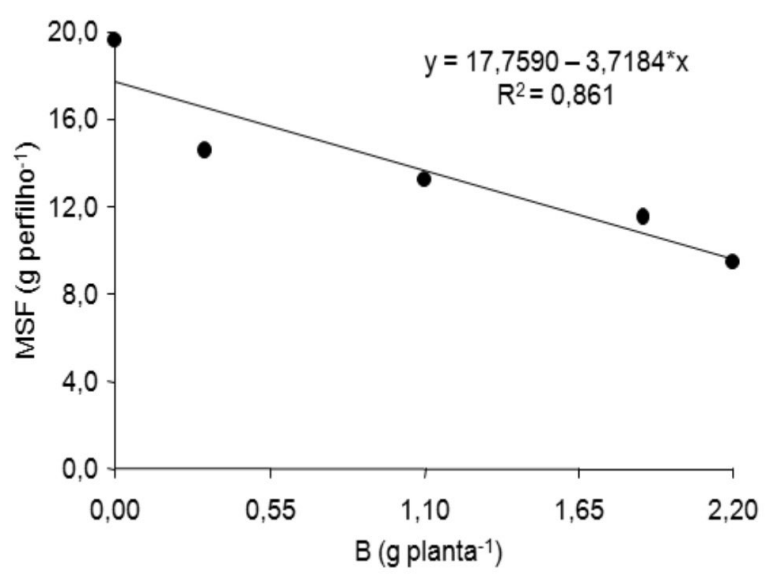

Figura 7. Peso da matéria seca foliar (MSF) dos perfilhos de plantas da bananeira 'Pacovan', com e sem poda, em três períodos pós-plantio. Médias com letras diferentes diferem pelo teste $\mathrm{F}$ a $1 \%$, em cada período pós-plantio.

Quanto ao teor de clorofila dos perfilhos aos 229 dias após o plantio, foram verificados efeitos significativos da combinação $\mathrm{N}$ e B, poda e interação entre $\mathrm{N}$ e B e poda sobre a clorofila total foliar de perfilhos de plantas da bananeira 'Pacovan' (Figura 8). 


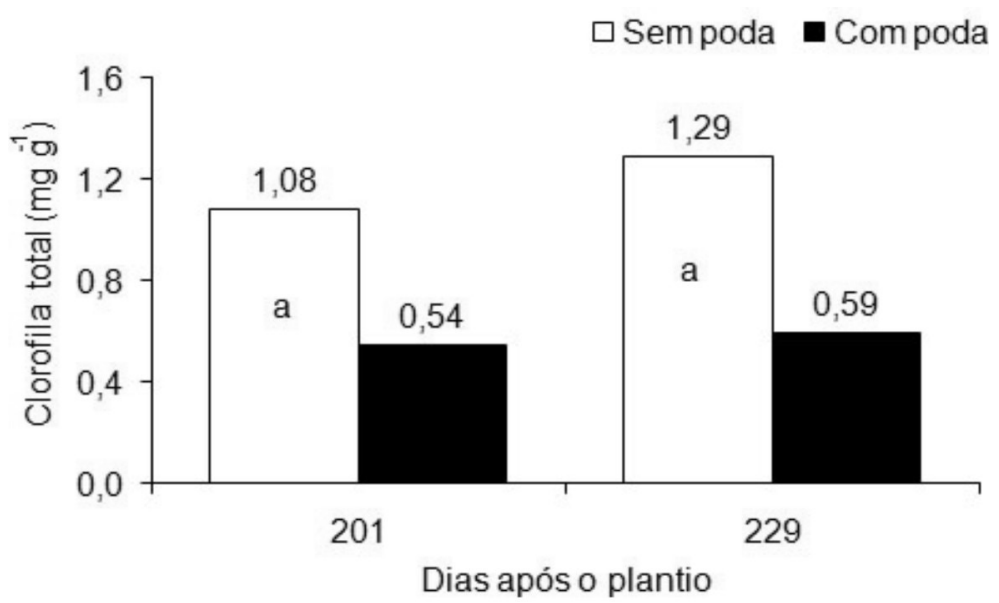

Figura 8. Teor de clorofila total foliar de perfilhos de plantas da bananeira 'Pacovan', com e sem poda, em dois períodos pós-plantio. Médias com letras diferentes diferem pelo teste F a 5\%, em cada período pós-plantio.

Aos 201 dias após o plantio, não houve efeito significativo de doses de $\mathrm{N}$ nem de B sobre a clorofila total foliar de perfilhos de plantas de bananeira 'Pacovan' com e sem poda. Resultado similar foi observado aos 229 dias após o plantio, para os perfilhos das plantas sem poda. Nos perfilhos das plantas de bananeira podadas houve efeito linear significativo das doses de B sobre o teor de clorofila total foliar.

O fato de ocorrer, nesta pesquisa, significativamente maior teor foliar de clorofila total justamente naqueles perfilhos de plantas sem poda (Figura 8), os quais apresentavam menores teores foliares de $\mathrm{N}$ que os perfilhos das plantas podadas, pode ser atribuído, em parte, provavelmente ao fato de os perfilhos originados das plantas com poda apresentarem maior expansão foliar (RONCHI et al., 2001) o que teria, conseqüentemente, resultado em uma maior diluição da clorofila nas suas folhas.

Na Figura 8, observa-se que o B exerceu, aos 229 dias após o plantio, influência linear positiva sobre o teor de clorofila total foliar dos perfilhos de plantas podadas da bananeira 'Pacovan', indicando que a clorofila total aumentou linearmente com o aumento das doses de B aplicadas, cujo incremento foi de $0,07 \mathrm{mg} \mathrm{g}^{-1}$ para cada $1 \mathrm{~g}$ planta $^{-1}$ de $\mathrm{B}$ adicionada ao solo.

Este resultado expressa a importância do B para a fotossíntese (PILBEAM; KIRKBY, 1983) e para a síntese de bases nitrogenadas como a uracila (ALBERT, 1968), a qual é componente essencial do RNA e, se ausente, afetará a proteossíntese. A propósito, a deficiência deste micronutriente nas bananeiras causa diversos sintomas, tais como: necrose nas folhas, listras amarelo-esbranquiçadas espalhadas na superfície da folha, goma no pseudocaule (BORGES; OLIVEIRA, 2000; CORDEIRO; BORGES, 2000), paralisação do crescimento das partes terminais e secagem das folhas novas (RAIJ, 1991).

Os valores médios de clorofila total foliar, aos 229 dias após o plantio (Figura 9), variaram de 0,51 a $0,74 \mathrm{mg} \mathrm{g}^{-1}$ nos perfilhos das plantas podadas e de 0,69 a $2,17 \mathrm{mg} \mathrm{g}^{-1}$ nos perfilhos das plantas sem poda. O maior teor de clorofila total foi observado no tratamento 7 (240 g planta $^{-1}$ de $\mathrm{N}+1,1$ g planta $^{-1}$ de B), seguido do tratamento 9 (120 g planta ${ }^{-1}$ de N $+1,1$ g planta $^{-1}$ de B), em perfilhos de plantas sem poda. 


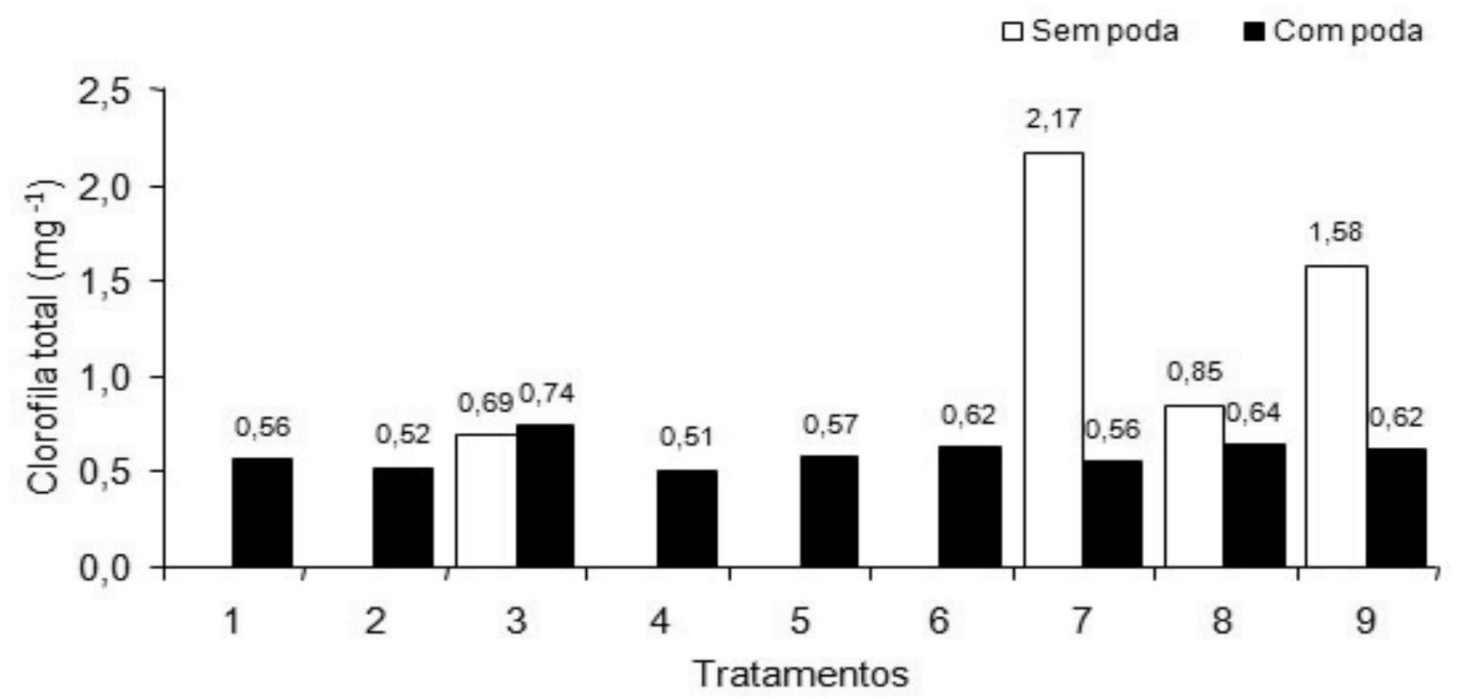

Figura 9. Teor de clorofila total foliar de perfilhos de plantas da bananeira 'Pacovan', em função dos tratamentos, com e sem poda, aos 229 dias após o plantio.

Nos estádios de desenvolvimento das plantas de bananeira 'Pacovan' aos 201 e 229 dias após o plantio, os teores médios de clorofila total foliar foram significativamente maiores nos perfilhos das plantas sem poda do que nos perfilhos das plantas com poda (Figura 14). Este resultado expressa o efeito da poda sobre a clorofila total foliar dos perfilhos das plantas de bananeira 'Pacovan'. O maior teor médio de clorofila total foliar, $1,29 \mathrm{mg} \mathrm{g}^{-1}$, foi observado nos perfilhos das plantas sem poda, aos 229 dias após o plantio, independentemente dos tratamentos entre doses de nitrogênio e de boro. Este resultado pode ser atribuído à redução da parte aérea das plantas matrizes em decorrência do efeito da poda.

\section{Conclusão}

A poda do pseudocaule com a eliminação da gema apical do rizoma aumentou o número, a altura do pseudocaule e a massa da matéria seca foliar e diminuiu o diâmetro do rizoma dos perfilhos e o teor de clorofila total nas folhas dos perfilhos da bananeira;
O incremento das doses de nitrogênio aumentou o número de folhas e a massa da matéria seca foliar e diminuiu o diâmetro do rizoma dos perfilhos das plantas podadas;

Em pelo menos uma das avaliações, o aumento das doses de boro diminuiu o número, a altura do pseudocaule, o diâmetro do rizoma e a massa da matéria seca foliar dos perfilhos das plantas podadas e aumentou a altura do pseudocaule dos perfilhos das plantas não podadas;

$\mathrm{O}$ incremento das doses de boro aumentou o teor foliar de clorofila total dos perfilhos das plantas podadas, 229 dias após o plantio.

\section{Referências}

ALBERT, L. S. Induction and antagonism of boronlike deficiency symptoms of tomato plants by selected nitrogen-bases. Plant Physiology, Lancaster, v. 43, n. 1, p. 51-54, 1968.

ALVES, E. J.; LIMA, M. B. Estabelecimento do bananal. In: CORDEIRO, Z. J. M. (Org.). Banana: produção: aspectos técnicos. Brasília, DF: Embrapa Comunicação para Transferência de Tecnologia, 2000. p. 73-82. (Frutas do Brasil, 1). 
ALVES, E. J.; MACEDO, M. M. C. Lurdinha, desbaste eficiente na bananeira. In: SEMINÁRIO DE TECNOLOGIA AGROPECUÁRIA INOVADORA PARA O NORDESTE, 1., 1986, Fortaleza. Anais... Fortaleza: BNB/ETENE, 1986, p. 460-462.

ANDRADE, F. W. R.; AMORIM, E. P. R.; ELOY, A. P.; RUFINO, M. J. Ocorrência de doenças em bananeiras no Estado de Alagoas. Summa Phytopathol, Botucatu, v. 35, n. 4, p. 305-309, 2009.

ARNON, D. I. Copper enzymes in isolated chloroplasts. Polyphenoloxidade in Beta vulgaris. Plant Physiology, Lancaster, v. 24, n. 1, p. 1-15, 1949.

AWAD, M.; CASTRO, P. R. C. Introdução à fisiologia vegetal. São Paulo: Nobel, 1983.

AZEVEDO, W. R. de; FAQUIN, V.; MOREIRA, F. M. de S.; OLIVEIRA JÚNIOR, A. C. de; LISBOA, C. C. Efeito do boro na nodulação da ervilha cultivada em solos de várzea. Pesquisa Agropecuária Brasileira, Brasília, DF, v. 37, n. 8, p. 1137-1143, 2002.

BERNARDO, W. F.; RODRIGUES, B. I.; CASSIERE NETO, P.; ANDO, A.; TULMANN NETO, A.; CERAVOlO, L. C.; MONTES, S. M. N. M. Micropropagação de baixo custo em bananeira cv. maçã em meios com diferentes fontes de carbono e avaliação da performance em campo das mudas produzidas. Revista Brasileira de Fruticultura, Jaboticabal, v. 26, n. 3, p. 503-506, 2004.

BORGES, A. L.; ALVES, E. J.; SILVA, S. de O. E.; SOUZA, L. da S.; MATOS, A. P. de; FANCELLI, M.; OLIVEIRA, A. M. G.; CORDEIRO, Z. J. M.; SILVEIRA, J. R. S.; COSTA, D. da C.; MEDINA, V. M.; OLIVEIRA, S. L. de; SOUZA, J. da S.; OLIVEIRA, R. P. de; CARDOSO, C. E. L.; MATSURA, F. C. A. U.; ALMEIDA, C. O. de. O Cultivo da banana. Cruz das Almas, BA: Embrapa-CNPMF, 1997. 109 p. (Circular Técnica, 27).

BORGES, A. L.; OLIVEIRA, A. M. G. Nutrição, calagem e adubação. In: CORDEIRO, Z. J. M. (Org.). Banana: produção: aspectos técnicos. Brasília, DF: Embrapa Comunicação para Transferência de Tecnologia, 2000, p. 47-59. (Frutas do Brasil, 1) CORDEIRO, Z. J. M.; BORGES, A. L. Problemas de causa abiótica e anormalidades de causa desconhecida. In: CORDEIRO, Z. J. M. (Org.). Banana. Fitossanidade. Brasília, DF: Embrapa Comunicação para Transferência de Tecnologia, 2000, p. 87-95.

COUCEIRO, M. A.; SIQUEIRA, D. L.; PEREIRA, W. E. Crescimento de explantes in vitro e de mudas de bananeira cv. Maçã, submetidas a doses de sacarose nas fases de enraizamento e aclimatação. Revista Ceres, Viçosa, MG, v. 48, n. 280, p. 615-627, 2001.

DECHEN, A. R.; BATAGLIA, O. C.; SANTOS, W. R. Conceitos fundamentais da interpretação da análise de plantas. In: PEREIRA, J. R.; FARIA, C. M. B. (Org.). Fertilizantes: insumo básico para agricultura e controle à fome. Petrolina: Sociedade Brasileira de Ciência do Solo, 1995. v. 1, p. 87-115.

DINIZ, J. D. N.; GONÇALVES, A. N.; HERNANDEZ, F. F. F.; TORRES, A. C. Absorção de macronutrientes por explantes de bananeira in vitro. Pesquisa Agropecuária Brasileira, Brasília, DF, v. 34, n. 7, p. 1201-1209, 1999.

EMPRESA BRASILEIRA DE PESQUISA AGROPECUÁRIA - EMBRAPA. Manual de análises químicas de solos, plantas e fertilizantes. Rio de Janeiro: Embrapa-CNPS, 1999.

Cultivo da banana para o agropolo JaguaribeApodi, Ceará. 2003. Embrapa-CNPAT. Disponível em: $<$ http://sistemasdeproducao.cnpta.embrapa.br $>$. Acesso em: 15 set. 2005 .

FONTES, P. S. F.; CARVALHO, A. J. C. de; CEREJA, B. S.; MARINHO, C. S.; MONNERAT, P. H. Avaliação do estado nutricional e do desenvolvimento da bananeira Prata-anã (Musa spp.) em função da adubação nitrogenada. Revista Brasileira de Fruticultura, Jaboticabal, v. 25, n. 1, p. 156-159, 2003.

KATAN, J.; GREENBERGER, A.; ALON, H.; GRINSTEN, A. Solar heating by polyethylene mulching for the control of diseases caused by soil-borne pathogens. Phytopathology, Palo Alto, v. 66, n. 5, p. 683-688, 1976.

LAHAV, E. Banana nutrition. In: GOWEN, S. (Ed.). Bananas and plantains. London: Chapman \& Hall, 1995.

LINDEN, M. M. G. A. Organização da produção da banana no município de Bananeiras (PB). 1985. Tese (Mestrado em Agronomia) - Departamento de Fitotecnia. Universidade Federal da Paraíba, Areia.

MEYER, B. S.; ANDERSON, D.; BOHNING, R.; FRATIANNE, D. Introdução a fisiologia vegetal. 2. ed. Coimbra: Fundação Caloustre Gulbenkian, 1983.

MOREIRA, R. S. Banana: teoria e prática de cultivo. 2. ed. São Paulo: Fundação Cargill, 1999. 1 CD-ROM.

PAVINATO, P. S.; AGUIAR, A.; CASTRO, G. S. A.; CRUSCIOL, C. A. C. Boro em arroz de terras altas cultivado em solução nutritiva. Bragantia, Campinas, v. 68, n. 3, p. 743-751, 2009.

PILBEAM, D. J.; KIRKBY, E. A. The physiological role of boron in plants. Journal of Plant Nutrition, New York, v. 6, n. 7, p. $563-582,1983$. 
PHILLIPS, I. D. J. Apical dominance. In: WILKIDS, M. D. (Ed.). The physiology of growth and development. London: Mc Graw-Hill, 1969.

RAIJ, B. V. Avaliação da fertilidade do solo. Piracicaba: Instituto da Potassa e do Fosfato, 1991.

RICCI, M. S. F.; ALMEIDA, D. L.; FERNANDES, M. C. A.; RIBEIRO, R. L. D.; AQUINO, A. M.; PEREIRA, J. C.; De-POLLI, H.; REIS, V. M.; EKLUND, C. R. de. Cyperus rotundus control by solarization. Biological Agriculture and Horticulture, Husbandry, v. 17, n. 2, p. 151-157, 1999.

RUGGIERO, C.; GOTTARDI, M. V. C. Avaliação do método de propagação rápida da bananeira. In: CONGRESSO IBEROAMERICANO, CONGRESSO IBÉRICO DE CIÊNCIAS HORTÍCOLAS, 18., 1997, Vilamoura. Anais... Vilamoura: Livraria Almedina. p. 130-135, 1997.

RUGGIERO, C.; SILVA, G. D. da; PERECIN, D.; A.; GOES; W. N. Método de propagação da bananeira (Musa sp) cultivar Pacovan: efeito de várias concentrações de BAP. Revista Brasileira de Fruticultura, Jaboticabal, v. 22, n. 3, p. 416-420, 2000.

RONCHI, C. P.; FONTES, P. C. R.; PEREIRA, P. R. G.; NUNES, J. C. S.; MARTINEZ, H. E. P. Índices de nitrogênio e de crescimento do tomateiro em solo e em solução nutritiva. Revista Ceres, Viçosa, MG, v. 48, n. 278, p. 469-484, 2001.
SANTOS, C. S. Nitrogênio e potássio aplicados via fertiirrigação em banana Pacovan. 2002. Tese (Mestrado em Agronomia) - Departamento de Fitotecnia. Universidade Federal da Paraíba, Areia.

SILVA, C. R. de R.; SOUTO, R. F.; MENEGUCCI, J. L. P. Propagação da bananeira. Informe Agropecuário, Belo Horizonte, v. 20, n. 196, p. 16-20, 1999.

SILVA, J. R. da; CORDEIRO, Z. J. M. Fitossanidade na exportação de banana. In: CORDEIRO, Z. J. M. (Org.). Banana. Fitossanidade. Brasília, DF: Embrapa Comunicação para Transferência de Tecnologia, 2000.

SOTO BALLESTERO, M. Bananas: cultivo y comercializacion. 2. ed. San José, Costa Rica: Litografia e Imprensa Lil, 1992.

SOUTO, R. F.; RODRIGUES, M. G. V.; RUGGIERO, C.; MENEGUCCI, J. L. P. Novas perspectivas em sistemas de implantação, condução e práticas de manejo da bananeira. Informe Agropecuário, Belo Horizonte, v. 20, n. 196, p. 10-15. 1999.

SOUZA, A. da S.; CORDEIRO, Z. J. M.; TRINDADE, A. V. Produção de mudas. In: CORDEIRO, Z. J. M. (Org.). Banana: produção: aspectos técnicos. Brasília, DF: Embrapa Comunicação para Transferência de Tecnologia, 2000. p. 39-46. 